\title{
BECAUSE IT IS FUN: INVESTIGATING MOTIVES OF FAKE NEWS SHARING WITH EXPLORATORY GAME QUESTS
}

\author{
Patrick Jost \\ Department of Computer Science \\ Norwegian University of Science and Technology, Trondheim, Norway
}

\begin{abstract}
Exploratory learning has become a widely applied, pedagogical concept. One approach to encourage exploratory knowledge creation are situated game experiences. Putting learners in quest-based environments can thereby support engagement through exploration and at the same time, allow for a variety of supportive learning strategies. However, examination of progress and investigation of success or motivational factors remain challenging in exploratory pedagogy. Evaluation in learning quests can interrupt the flow experience that supports engaging and successful learning in exploratory environments.

This paper presents an approach for unobtrusive dialogic investigation in quest-based learning environments. Building on the results of an existing exploratory game quest to raise privacy awareness, the study conducts a dual between-subjects investigation to identify the motives of sharing fake news. The study, therefore, extends a mini-quest with a character to build a dialogic investigation for evaluating the intentions behind sharing of fake headlines. Concurrently, the impact on perception of flow and the robustness of the suggested dialogic inquiry is assessed by comparison to the prior non-dialogic evaluation.

The results of the experiment with participating educators and students $(N=92)$ from two European universities confirm students more likely share fake news than educators and suggests hedonic rather than pragmatic motives as drivers of the sharing decision. The dialogic investigation with the mini-quest shows that students perceive fake news headlines as significantly funnier than educators while also spending less time reflecting if they are real or fake. Flow experience did not improve significantly by changing to dialogic questioning. However, positive tendencies in all flow sub-measures indicate that adding a character and inquiring with dialogue rather supports than breaks the sense fluency in exploratory learning quests. Implications for the design of analytical mini-quests as well as further research directions are outlined conclusively.
\end{abstract}

\section{KEYWORDS}

Exploratory Learning, Evaluative Mini-Quests, Game-based Investigation, Serious Games, Decision Making, Fake News Sharing

\section{BACKGROUND AND RESEARCH OBJECTIVES}

Deciding if information is trustworthy has become an invaluable skill in our environment that is technically and socially connected in every perspective. Teaching about (digital) information and the value of private information is thus an educational mission to educators. However, the skill to judge if information is honest or if sharing of private data is appropriate or not strongly depends on the context of social interaction. Whereas in one situation it might be appropriate to share (e.g. within a close friend's chat group), this shared information can leave context and become a severe privacy concern in another situation as pointed out by Nissenbaum (2009). Aside from this contextual permeability, the indelible nature of digital data in social networks complicates decisions on what can cause privacy issues. Simply put, once shared, it cannot merely be deleted sometime later when a contextual change is becoming evident.

Sharing and thus multiplying and spreading potentially false and harmful news on networks, for example, is a process that cannot be just stopped by one authority. Even a relatively obvious hoax can therefore spread and circulate in social media without being identified for an extended period. Notably, such hoaxes are not only a nuisance but can develop into serious threats, conflicts and consequences affecting politics and policies 
(Zannettou et al., 2019) but as well personal life and security (Muthaqin, 2020). As spreading wrong information is also a fast-rising issue on social media (Sulistyawan \& Pinilih, 2019), researchers identified a lack of media literacy (Higdon, 2020) leading to the spread of false news.

Our recent investigation with an exploratory game to raise awareness about data sharing concerns (Jost, 2020) confirmed that students are considerably more susceptible to share fake news headlines than educators. However, for finding adequate pedagogical strategies to raise media literacy and awareness of possible dire consequences in sharing of hoaxes, it is essential to learn more about the motives that drive the younger generation in sharing fake news. In this regard, Leeder et al. (2019) recently found that students' willingness to share news was unrelated to trustworthiness evaluations and accuracy of identification as real/fake. This present study is consequently extending the research objective to learn more about the motives involved in students' fake news sharing decision. In addition to assessing sharing decisions and the pragmatic quality of real/fake the investigation is extended with evaluating the emotional/hedonic quality of fun perceived from the news headline following the model of Hassenzahl (2007).

As several researchers have established the benefits of exploratory pedagogical approaches such as situated learning/cognition (Lave \& Wenger, 1991) and problem-based learning (Ertmer \& Glazewski, 2018) the problem-solving practice is generally also in line with exploratory game experiences (de Freitas \& Oliver, 2006). Quests as inherently problem-solving endeavours can be seen as challenges to overcome by engaging in a situated problem-solving task. They can allow learners to learn from relatable real-world oriented scenarios and learn from experiencing failure and consequences in a safe environment (Dahlin et al., 2018).

Further, the social frame where dialogues happen in a problem situation with a peer or in a group could be designed in quests and influential factors on decisions judged with evaluation. People could meet other players or game entities such as virtual agents to engage in a dialogue. Similarly, advanced chatbot technology could be applied (Bergen et al., 2018) in problem situations to investigate influential factors on decisions about sharing personal data.

\subsection{Evaluation in Exploratory Game-Based Learning}

Beneficially, exploration can promote engagement in learning environments when combined with the concept of knowledge discovery (Yee \& Ducheneaut, 2018). Eventually, the exploratory quest could represent a situated learning environment with discoverable points-of-interests (POI) which present decision challenges to overcome. Such POI, however, may also be configured as investigative mini-quest scenarios that allow assessment of learner progress or research questions. Nevertheless, to allow a reliable assessment of sharing decisions or other measures, an investigative game experience requires balancing of cognitive influences (Jost, 2020; Jost et al., 2020). Story aligned inquiry in dialogical form could thereby help both, controlled evaluation and unobtrusive investigation for maintaining an engaging game flow without interruption of a narrative (Nakamura \& Csikszentmihalyi, 2009).

Having a dialogue, of course, requires characters and a context fitting the narrative. In other words, a situation, and thus possible extraneous workload originating from presentation or interaction with it (Sweller et al., 2011). Ifenthaler et al. (2012) provide a good overview of learner-centric game-based assessment (GBA) with a recent update to the state of research (Ifenthaler \& Kim, 2019) including data-driven approaches informing event-streams, technical threshold concepts and games as formative assessment tools. Several discussed methods of assessment could thereby extend the investigative approach to a broader social research context. Effectively, extending the learning to an investigation approach contributing to domain research goals. When, for example, evaluating exploratory learning quests that include dialogic situations, knowledge creation in decision-making influences could contribute to the scientific knowledge base of cognition and risk-taking. Taking this perspective essentially evolves GBA to a bidirectional research instrument that transmits as well as emits knowledge. While the natural sciences intensively apply parametric simulations for knowledge creation, the social context possesses a hedonic dimension that is difficult to quantify. When trying to evaluate a decision in a narrative quest, for example, the visual presentation of an artificial character matters not only cognitively but at the same time emotionally. Not dissimilar to a real-world interviewer and relatedly subject to emotional biases or preconceptions (Baylor, 2009; Veletsianos, 2010). Which leads to the question of what hedonic influences a dialogic evaluation entails and how they would affect evaluation results or reliability of complementary metrics such as unobtrusive embedded measurements/analysis. The prior test cycle of the presented exploratory learning quest has demonstrated expectable and accurate assessment of fake news sharing tendencies (Jost, 2020) with decision-making metrics while reaching adequate perceptions of flow. As expected, a higher propensity of sharing fake news was found with students compared to educators. 


\subsection{Research Objectives}

Consequently, to better understand this sharing tendency for pedagogical alignment, this study extends the evaluative mini-quest to assess the pragmatic/hedonic motives of sharing. In other words, following the question, if students inadvertently share more because they also are less able to rationally identify fake news or deliberately because the headlines trigger a more impulsive sense of hedonic pleasure. Moreover, the mini-quest is adapted to a more relatable real-world scenario to encourage contextual knowledge creation and maintain flow by aligning to the overarching narrative.

Therefore, the participant engages in a dialogue on the qualities of fake news headlines and sharing intentions with a character from the overarching exploratory environment. In comparing the non-dialogic assessment with the quest-based evaluation robustness of decision-making measures and influences of the character-based inquiry on fluency and absorption of the quest experience is valued. Consequently, the two research objectives of this present study aim to contribute to:

1. Identifying the motives behind students' tendency to sharing fake news headlines to guide pedagogical approaches for learning about the threats of data sharing.

2. Evaluating the assessment of decision making with situated mini-quests regarding the robustness of measures and influences on flow perception when combining metrics with character visualisation and dialogic inquiry.

\section{EMPIRICAL RESEARCH APPROACH}

\subsection{The Quest Game-Frame: Configuration of a Dialogic Mini-Quest}

To address the first research question, the established reflection time metrics of the prior evaluation cycle were again applied. Just as well as the overarching exploratory learning quest implemented with the Quest Game-Frame (QGF) (Jost, 2020). However, in the "City of Data Sharing", the prepared mini-quest for assessing the sharing decision tendencies regarding real/fake news was extended with a character visualisation (Figure 1) and dialogic questioning instead of prior simple text box indicating slider input without a relation to the overarching quest. The character named "John" was a friend of the protagonist met in the mini-quest before and engaged in a dialogue when both noticed a newspaper stand at the sidewalk. The character was designed and integrated into the QGF by using the library of Adobe Fuse CC/mixamo.com.
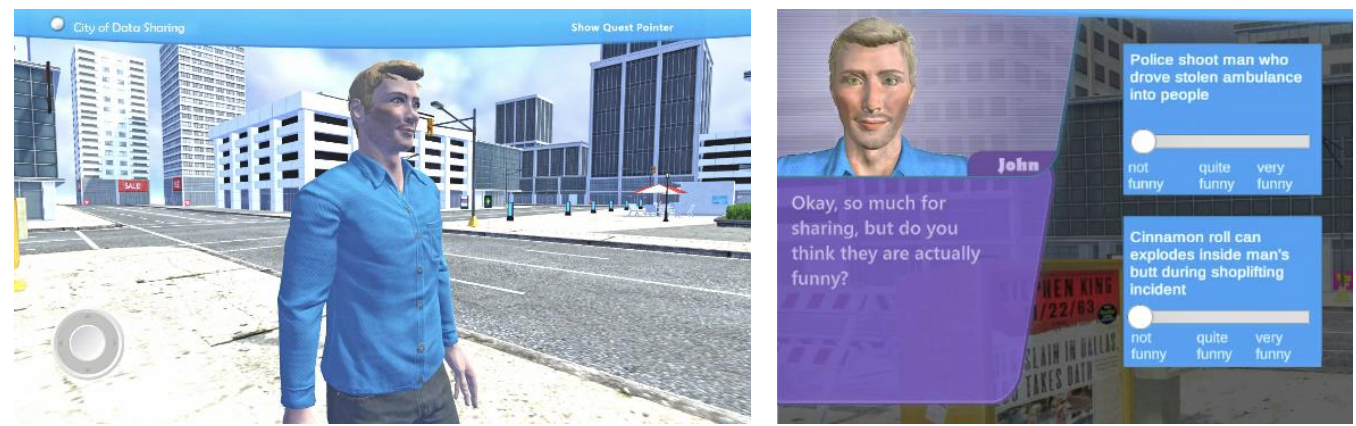

Figure 1. Exploratory quest environment (left) and dialogic mini-quest to investigate motives in fake news sharing

The mini-quest triggered when the player walked into a POI in the city, or the exploratory 3D environment, respectively. A static image of John was displayed while he was first starting to ask how likely the protagonist would share some of the headlines to replicate the prior user study in a dialogic form. As before, it was made clear that some of the six headlines are real and some are fake news and asked how likely s/he would share the news. However, John then progressed to ask the protagonist to express her/his perception of fun regarding the headlines. After that, he challenged the participant to judge how likely they are real or fake. The same headlines were used as in the prior study (Jost, 2020) to maintain comparability of study results. Equally, the same rating scales (from 1 to 10) were applied on all three dialogical stages - sharing intention, perception of fun and 
perception of reality). Figure 1 displays the extended dialogic evaluation. For evaluating flow experience, again a digital rating possibility of the 10-item flow short scale (ranging from 1 to 7) (Rheinberg et al., 2002) was presented following the last quest, and it was optional to provide this feedback. The exploratory quest game was built for web browser supporting WebGL 2.0. No personal data was assessed; all players were prompted with information on data collection and only advanced to playing after informed consent.

\subsection{Research Design and Hypotheses}

To investigate the two outlined objectives, both examinations followed a between-group design. The investigation with extended dialogic mini-quest was planned to match the prior study cycle for comparability of results. Therefore, educators/students from the same two universities in Austria and Norway but different departments/courses were invited to take part in the study. Two members of the departments invited to engage in the quest-based exploration game via e-mail to their colleagues and students.

The experimental design for investigating the motives of sharing decisions (research objective 1) is outlined in Figure 2 and combines the reflection metrics established in the preceding study with character dialogue on sharing intention and pragmatic/hedonic qualities regarding the fake headlines.

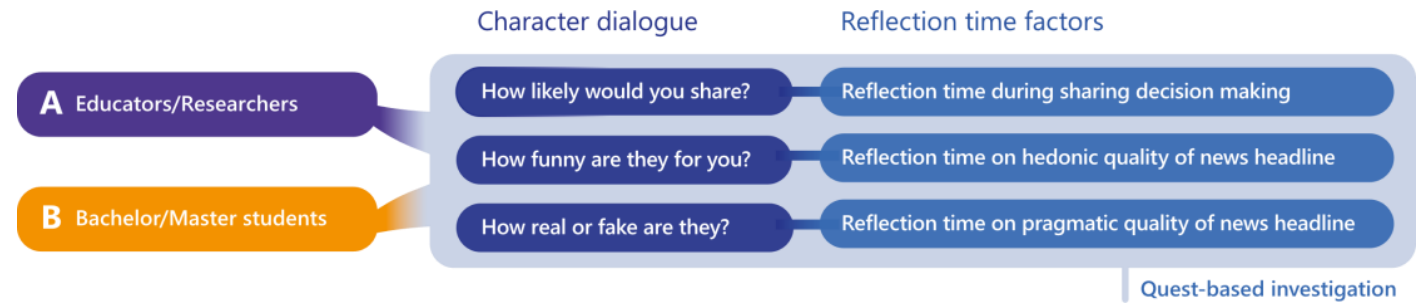

Figure 2. Experimental design for investigating fake news sharing motives with a dialogic mini-quest [RO1]

For monitoring the impact of the dialogue-oriented evaluation with a visualised character on sharing, perception of fluency and absorption by the experience (research objective 2), the results of the group of the earlier study were valued against the present study group (Figure 3).

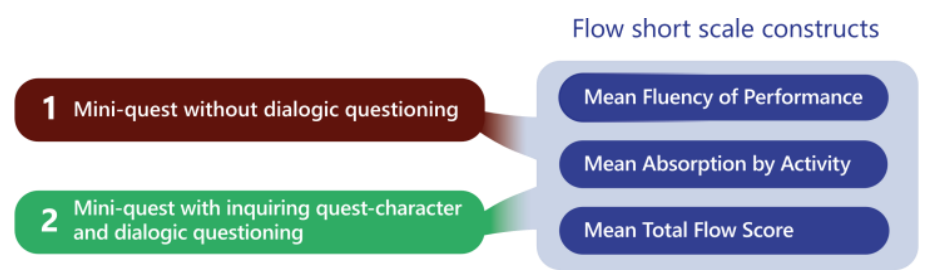

Figure 3. Experimental design to evaluate influences of dialogic investigation on an engaging experience [RO2]

According to the research objectives, the null hypotheses established for the empirical investigation were:

$H_{O A}$ : 'There are no significant differences between educators and students in the propensity of sharing news headlines.'

$H_{O B}$ : 'Educators and students do not differ in their perception of news headlines as fun or real.'

$H_{O C \text { : }}$ 'There are no significant differences in experiencing flow when evaluating decision making situations with visualised dialogic questioning compared to the non-dialogic inquiry.'

\subsection{Data Collection and Analysis}

The invitations were distributed to two research groups and three university courses at an Austrian and a Norwegian university. Ethical approval for the project was granted by the Norwegian Centre for Research Data. Informed consent was obtained before participation with an introductory screen before starting the quest. Data was collected with the mini-quest evaluation modules of the QGF (Jost, 2020) by the provided dialogue scoring and reflection metrics. Using in-game events, each mini-quest result was stored non person-related over a secure connection to the data controller's database. E-mail invitations resulted in 92 participations from 
two departments and three university courses. All participants (Table 1) played the game using a web browser. Data was subsequently analysed using IBM SPSS Statistics (version 25).

Table 1. Distribution of participation in dialogic mini-quest [between-subjects experiment A/B]

\begin{tabular}{|c|c|c|c|c|c|c|c|c|c|c|}
\hline \multicolumn{4}{|c|}{ Participators in dialogic mini-quest } & \multicolumn{7}{|c|}{ Distribution by age group } \\
\hline & Educators & Students & $\sum$ & $16-19$ & $20-29$ & $30-39$ & $40-49$ & $50-59$ & $60-69$ & $\sum$ \\
\hline$N$ & 25 & 67 & 92 & 10 & 57 & 14 & 7 & 3 & 1 & 92 \\
\hline Quota \% & 30.8 & 69.2 & 100 & 9.3 & 61.7 & 15.9 & 8.5 & 3.7 & 0.9 & 100 \\
\hline
\end{tabular}

\section{RESULTS}

The collected data of participation entries was not consistently normally distributed but showed comparable distribution and homogeneity of variance; thus non-parametric Mann-Whitney $U$ analysis $(\alpha=0.05)$ was conducted following Field (2009). Statistical testing revealed significant differences on sharing tendencies between educators and students on both, sharing real and fake news as well as in hedonic perception of fake news as fun and the reflection time when judging veracity (Figures Figure 4/Figure 5; Table 2).
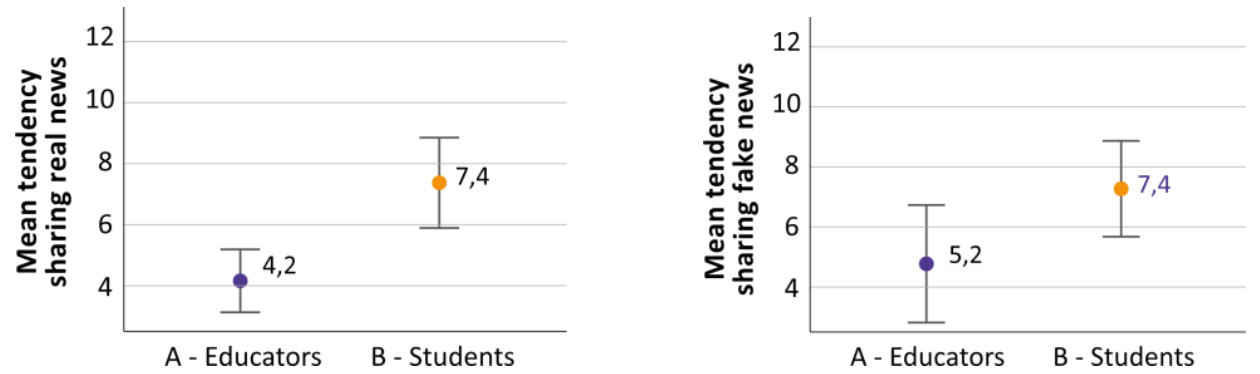

Figure 4. Mean tendency to decide sharing real/fake news [min 3; $\max 30]$
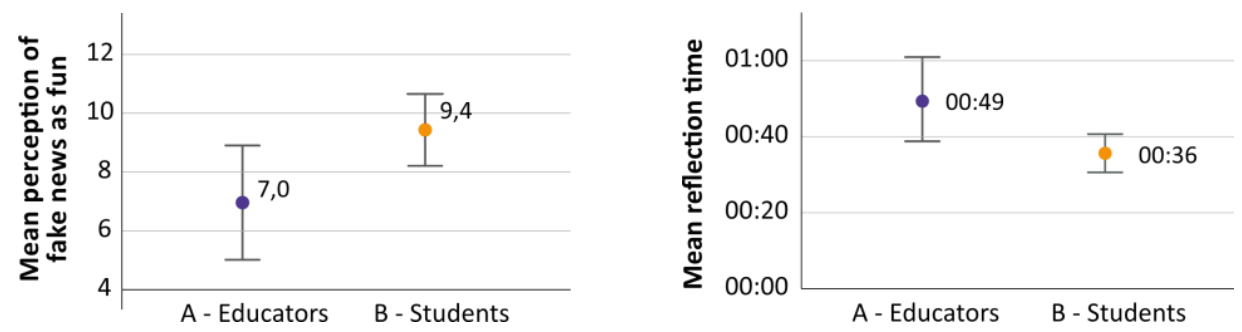

Figure 5. Mean perception of fake news as fun [ $\min 3 ; \max 30]$ and mean reflection time on real/fake decision in seconds [mm:ss]

Although the median does not differ in tendency of sharing fake news, the mean rank comparison revealed a significant difference for tendency of sharing fake news originating from a smaller range (Table 2) which is better displayed in this case when looking at the mean (Campbell, 2006). Consequently, the results suggest rejecting the null hypotheses $H_{O A}$ as there are differences in sharing tendencies and $H_{O B}$ since students and educators differ in their perception of news headlines as fun or real. Statistical results showed no significant differences when looking on flow perception by comparing study group $1(N=31)$ of the preceding study to the 75 participants of the present study 2 that provided the optional feedback. The extension to dialogic evaluation was neither perceived significantly different in perception of fluency of performance between group $1(M=4.64)$ and $2(M=4.94), U=1010, z=-1.06, p=.289$ nor absorption of activity between the first study $(M=3.44)$ and the second $(M=3.52), U=1075, z=-.61, p=.543$. 
Table 2. Statistically significant differences between educators and students when deciding on sharing real/fake news

\begin{tabular}{|c|c|c|c|c|c|c|c|c|}
\hline & & Mean & Median & Range & $U$ & $z$ & $p$ & $r$ \\
\hline $\begin{array}{l}\text { Reflection on real/fake decision } \\
\text { (pragmatic quality) }\end{array}$ & $\begin{array}{l}\text { A } \\
\text { B }\end{array}$ & $\begin{array}{l}0: 00: 49 \\
0: 00: 36\end{array}$ & $\begin{array}{l}0: 00: 46 \\
0: 00: 34\end{array}$ & $\begin{array}{l}0: 02: 29 \\
0: 01: 30\end{array}$ & 597 & -2.11 & .035 & .22 \\
\hline $\begin{array}{l}\text { Tendency to share real news } \\
{[\min 3 ; \max 30]}\end{array}$ & $\begin{array}{l}\mathrm{A} \\
\mathrm{B}\end{array}$ & $\begin{array}{l}4,16 \\
7,37\end{array}$ & $\begin{array}{l}3 \\
5\end{array}$ & $\begin{array}{c}9 \\
27\end{array}$ & 545.5 & -2.82 & .005 & .29 \\
\hline $\begin{array}{l}\text { Tendency to share fake news } \\
{[\min 3 ; \max 30]}\end{array}$ & $\begin{array}{l}\mathrm{A} \\
\mathrm{B}\end{array}$ & $\begin{array}{l}5,20 \\
7,43\end{array}$ & $\begin{array}{l}3 \\
3\end{array}$ & $\begin{array}{l}17 \\
27\end{array}$ & 634.5 & -1.98 & .047 & .21 \\
\hline $\begin{array}{l}\text { Perception of fake news as fun } \\
\text { (hedonic quality) [min } 3 ; \max 30]\end{array}$ & $\begin{array}{l}\text { A } \\
\text { B }\end{array}$ & $\begin{array}{l}6,96 \\
9,43\end{array}$ & $\begin{array}{l}5 \\
9\end{array}$ & $\begin{array}{l}18 \\
18\end{array}$ & 582 & -2.28 & .023 & .24 \\
\hline
\end{tabular}

The total sense of flow was as well not differing significantly between the group investigated without dialogical evaluation $(M=4.16)$ and the group assessed with a dialogue $(M=4.37), U=1054, z=-.75$, $p=.451$. Thus, the analysis indicates to keep hypothesis $H_{O C}$.

\section{DISCUSSION}

\subsection{Motives for Sharing Fake News and Reflective Decision Making}

When analysing what the results regarding the first research objective, the study disclosed primarily two valuable insights on sharing of fake headlines and the motives behind propensity to share.

First, the results made again clear that students are more inclined to share fake headlines than educators. Thus, confirming the findings of the preceding study on sharing propensity of fake news. However, they are also generally more willing to share headlines than educators regardless of the grade of veracity. The tendency was notable in the preceding study and likely strengthened to significance in the present study by the larger sample.

Secondly, students shared fake news more because they were perceived as fun, not because they were considered real or fake. Compared to educators, students perceived the fake headlines as $34 \%$ more amusing, and obviously, they are not determined to reflect too long about the truth of a headline either. When it comes to judging the authenticity of headlines, the empirical evidence of this study showed students are deciding on average $36 \%$ faster than educators on the pragmatic decision between fact or fake. This hedonic/pragmatic relation is in line with the findings of Leeder (2019) and suggests that the students' sharing attitude regarding fake news is more related to a faster and instinctive decision making (Evans, 2003) than the educators' approach.

Taking the educators view, this recommends fostering explorative, problem-based learning approaches since they can encourage critical thinking and help contextual knowledge creation (Kumar \& Refaei, 2017). Exploratory quest frames could thereby function as balancing construct in three ways, a pathway to follow learner progress (Ruipérez-Valiente et al., 2016) (i.e. the learning goal), a supportive environment for aligning rewarding game achievements and engaging narrative plot situations (i.e. the game goal) and investigating decision-making process and outcome for knowledge creation considering situated contexts (i.e. the domain goal) (Jost, 2020). However, balancing these goals is a continuous requirement for achieving successful outcomes on all points of this intertwined triangle. Comparable to balancing flow of a user experience but with the additional challenge of achieving learner progress.

\subsection{Implications for Evaluation in Exploratory Game Quests}

Accordingly, this study monitored the influences on flow experience when aligning decision making investigation with a more quest-based dialogic inquiry. When interpreting the data for this second research objective, also two main implications arise for the design of evaluations with mini-quests.

First of all, dialogue-based situated investigation aligned on overarching narrative with a pictorial character does not change the perception of game flow. Although, both flow sub-constructs and total flow perception show positive tendency, the addition of dialogue with pictorial impression of a character alone is not significantly changing flow experience. Since there is a generally positive trend, the data nonetheless 
suggests following this approach with further investigation for improvements. In particular, as this finding is also the origin of the next subsequent design implication for exploratory environments.

Evaluation with mini-quests displays investigative robustness when applied in situated decision-making research. Adding character visualisation and adapting the inquiry to a dialogue-style inquiry confirmed prior results on sharing decisions. Students' again were found to be more susceptible to spreading fake news than educators. Considered both implications together, dialogic evaluation with pictured non-playing characters is not showing great benefits for flow experience, but on the other hand, is not breaking or distorting it either. This suggests following a point-of-interest structure and aligning investigations in dialogic mini-quests along a narrative can be a way to probe for success factors on decision making. By considering the domain goals arranged in an overarching exploratory scaffolding, situated mini-quests could be applied for probing success factors that influence different outcomes. Specifically, when considering dynamic adaptions of decision situations and potential influences to examine. The configuration of such a game approach should, however, be considered starting with the conceptual phase to balance the experience accordingly.

\subsection{Limitations and Further Research Trails}

This study revealed valuable insight and conclusive implications on the two research objectives while also confirming results of the preceding examination cycle with the investigative quest environment. Nonetheless, the results must be considered with constraints. One reason is that the binational sampling was limited to universities and thus a specific population. The findings cannot be translated directly to other contexts such as organisational or industrial investigation scenarios. Further research approaches should also apply the quest game frame to other use cases than data sharing to create insight on balancing factors for quest configuration. Another limitation is the visualisation of the character that has been pre-determined by applying a character creation tool defining an abstract appearance. Implications on the design of mini-quest evaluations should be regarded concerning similar visual styles. More investigation is needed to disclose influences from other visual representations with a dialogic inquiry, including photographs, videos, or animated characters. Eventually, the possibilities of generative media should be explored with quest-based scenarios to extend the possibilities of mini-quest probing.

\section{CONCLUSION}

This study extended a situated mini-quest in an exploratory learning environment with dialogic examination and character visuals to investigate motives of sharing fake news headlines as well as influences from dialogic evaluation on the measures. The results demonstrated robustness of the quest-based investigation approach by confirming results of a prior investigation cycle in the finding that students more likely share fake headlines than educators. More importantly, however, the findings of this examination disclosed the motives of sharing are rather originating from a more hedonic perception of the fake headlines than from judging authenticity. Exploratory, problem-based approaches such as quest-based learning can thus be an appropriate strategy for improving critical reflection on the threats of sharing false information. Additionally, the results suggest that while the dialogic evaluation the designed mini-quest is not improving flow experience, it is not breaking it either. Mini-quests that assemble to learning pathways in an overarching exploratory environment bears the potential to be both, motivating for students and knowledge-creating for researchers. Future research can follow several significant strands: advance unobtrusive in-game evaluation that regards situated context, examine the potentials of generative media for creating social environments (e.g. generated characters), or investigate how game-based quests can become a tool for meaningful social knowledge creation. Ultimately, balancing the interdependent objectives of learning, engagement, and assessment remains a continuous challenge.

\section{ACKNOWLEDGEMENT}

This research was supported by the Research Council of Norway (Norges Forskningsråd) by funding the IKTPLUSS project ALerT, \#270969. 


\section{REFERENCES}

Baylor, A. L. (2009). Promoting motivation with virtual agents and avatars: Role of visual presence and appearance. Philosophical Transactions of the Royal Society B: Biological Sciences, 364(1535), 3559-3565.

Bergen, E., Solberg, D. F., Sæthre, T. H., \& Divitini, M. (2018). Supporting the Co-design of Games for Privacy Awareness. International Conference on Interactive Collaborative Learning, 888-899.

Campbell, M. J. (2006). Teaching non-parametric statistics to students in health sciences. In ICOTS 7. IASE, ISI Salvador, Bahia, Brazil.

Dahlin, K. B., Chuang, Y.-T., \& Roulet, T. J. (2018). Opportunity, Motivation, and Ability to Learn from Failures and Errors: Review, Synthesis, and Ways to Move Forward. Academy of Management Annals, 12(1), 252-277.

de Freitas, S., \& Oliver, M. (2006). How can exploratory learning with games and simulations within the curriculum be most effectively evaluated? Computers \& Education, 46(3), 249-264.

Ertmer, P. A., \& Glazewski, K. D. (2018). Problem-based learning: Essential design characteristics. Trends and Issues in Instructional Design \& Technology, 286-295.

Evans, J. S. B. (2003). In two minds: Dual-process accounts of reasoning. Trends in Cognitive Sciences, 7(10), 454-459.

Field, A. P. (2009). Discovering statistics using SPSS: (And sex, drugs and rock ' $n$ ' roll) (3rd ed). SAGE Publications.

Hassenzahl, M. (2007). The hedonic/pragmatic model of user experience. Towards a UX Manifesto. HCI 2007, Lancaster, UK.

Higdon, N. (2020). The Anatomy of Fake News: A Critical News Literacy Education. Univ of California Press.

Ifenthaler, D., Eseryel, D., \& Ge, X. (Eds.). (2012). Assessment in Game-Based Learning. Springer New York.

Ifenthaler, D., \& Kim, Y. J. (Eds.). (2019). Game-Based Assessment Revisited. Springer International Publishing.

Jost, P. (2020). The Quest Game-Frame: Balancing Serious Games for Investigating Privacy Decisions. In Proceedings of the 11th Scandinavian Conference on Information Systems (SCIS2020) (pp. 1-17). Association for Information Systems (AIS). https://aisel.aisnet.org/scis2020/5/

Jost, P., Cobb, S., \& Hämmerle, I. (2020). Reality-based interaction affecting mental workload in virtual reality mental arithmetic training. Behaviour \& Information Technology, 39(10), 1062-1078. https://doi.org/10.1080/0144929X.2019.1641228

Kumar, R., \& Refaei, B. (2017). Problem-based learning pedagogy fosters students' critical thinking about writing. Interdisciplinary Journal of Problem-Based Learning, 11(2).

Lave, J., \& Wenger, E. (1991). Situated learning: Legitimate peripheral participation. Cambridge university press.

Leeder, C. (2019). How college students evaluate and share "fake news" stories. Library \& Information Science Research, 4l(3), 100967.

Muthaqin, D. I. (2020). Rehabilitation Concept of Legal Protection for Citizen in Hoax Defamation. 2nd Annual Civic Education Conference (ACEC 2019), 82-86.

Nakamura, J., \& Csikszentmihalyi, M. (2009). Flow theory and research. In C. R. Snyder \& S. J. Lopez (Eds.), Handbook of positive psychology (pp. 195-206). Oxford University Press.

Nissenbaum, H. (2009). Privacy in context: Technology, policy, and the integrity of social life. Stanford University Press.

Rheinberg, F., Engeser, S., \& Vollmeyer, R. (2002). Measuring components of flow: The Flow-Short-Scale. Proceedings of the 1st International Positive Psychology Summit.

Ruipérez-Valiente, J. A., Muñoz-Merino, P. J., \& Kloos, C. D. (2016). An analysis of the use of badges in an educational experiment. 2016 IEEE Frontiers in Education Conference (FIE), 1-8.

Sulistyawan, A. Y., \& Pinilih, S. A. G. (2019). The Reality of Spreading Hoaxes on Social Media: A Sociolegal Approach. 2nd International Conference on Indonesian Legal Studies (ICILS 2019), 436-441.

Sweller, J., Ayres, P., \& Kalyuga, S. (2011). Cognitive Load Theory in Perspective. In J. Sweller, P. Ayres, \& S. Kalyuga, Cognitive Load Theory (pp. 237-242). Springer New York.

Veletsianos, G. (2010). Contextually relevant pedagogical agents: Visual appearance, stereotypes, and first impressions and their impact on learning. Computers \& Education, 55(2), 576-585.

Yee, N., \& Ducheneaut, N. (2018). Gamer motivation profiling: Uses and applications. In Games User Research (First edition, pp. 485-490). Oxford University Press.

Zannettou, S., Sirivianos, M., Blackburn, J., \& Kourtellis, N. (2019). The web of false information: Rumors, fake news, hoaxes, clickbait, and various other shenanigans. Journal of Data and Information Quality (JDIQ), 11(3), 1-37. 